IOS Press

\title{
An NFC based context-aware solution for access to bibliographic sources in university environments
}

\author{
Francisco Borrego-Jaraba*, Gonzalo Cerruela García, Irene Luque Ruiz and \\ Miguel Ángel Gómez-Nieto \\ University of Córdoba, Department of Computing and Numerical Analysis, Campus de Rabanales, Albert Einstein \\ Building, E-14071 Córdoba, Spain \\ E-mail: \{fborrego,gcerruela,iluque,mangel\}@uco.es
}

\begin{abstract}
The advance of mobile and wireless technologies in recent years is permitting the development of new and more complex context-aware and pervasive systems. These applications cover a wide spectrum of problems, sectors, scenarios, and environments that aim to build smart environments, such as educative innovation. In this paper we present a proposal for a pervasive system providing students the access to bibliographic sources recommended by teachers on the subjects or courses on which the students are enrolled. In order to define the educational contents of a subject or course the IMS Learning Design standard has been used. Finally, we describe the use of NFC (Near Field Communication) for the development of the proposed pervasive system, showing the usefulness of the proposal and user acceptance.
\end{abstract}

Keywords: Near field communication, pervasive system, ambient intelligence, IMS learning design, ontology

\section{Introduction}

The European Higher Education Area (EHEA) $[11,45]$ is the objective of the Bologna Declaration [7] to create more comparable, compatible and coherent systems of higher education in Europe. In order to adapt the universities to EHEA it is necessary to develop systems based on the use of new technologies, thereby helping the educators to set-up powerful learning experiences for students. Computers, Internet, and other tools offer the promise of significant improvements in teaching and learning not only using electronic mails or forums, but also for virtual teaching, sharing information, and so on.

It is evident that Universities need to make big changes in teaching-learning models and also in the quantity, quality and type of services that they offer to society. This involves the introduction of new management and organization measures, control and quality assurance of education, and modernization of the University through the full implementation of new technologies in all university areas.

As the University is a teaching entity there is a need for ubiquitous applications that help the student to improve his/her academic experience, such as ubiquitous games to motivate students, help in the library to find the material, tutorials management, attending control systems, etc. [8,33].

The visionary idea of Weiser [49] about ubiquitous or pervasive computing is emerging thanks to the advance in mobile and wireless technologies. The ubiquitous paradigm allows the development of active and mobile environments, allowing access to a huge amount of information and its processing, independent of the users' location, thanks to the use of computational elements intercommunicated by wireless networks, radio, GSM, etc.; elements embedded in furniture, belongings, posters, machines, books, etc.

The ubiquitous computing idea has recently evolved into a more general paradigm known as Am-

\footnotetext{
*Corresponding author. E-mail: fborrego@uco.es.
} 
bient Intelligence (AmI). Ambient Intelligence represents a new generation of user-centred computing environments aiming to find new ways to obtain a better integration of information technology for devices and activities in everyday life. AmI [24,25] consists of the creation of living environments (called intelligent environments) [26] where users interact in a natural and intuitive way with computational services facilitating the completion of the user's everyday tasks, whether for leisure, help or work assistance [1]. In these environments, the user is surrounded by ubiquitous resources embedded in augmented objects [20].

In this vision of the future that AmI forecasts, the model of user interaction, information visualization, access personalization, and context sensitivity play a very important role that has been studied by different authors [2,31], where several models, paradigms and applications to learning environments [29] have been stated have been proposed.

Ubiquitous or pervasive computing research is characterized primarily by a concern with potential future computational worlds [50]. This notion situates research as the initial step upon a path of technological development inspired by an explicit vision of possible future relationships between people, practices, and technologies.

An interesting technology that has emerged in recent years that seems to be an ideal possibility for the development of pervasive systems is Near Field Communication (NFC) technology [13]. NFC provides a natural interaction path between the user and its environment that makes it the ideal candidate for the development of ambient intelligence.

NFC is based on RFID (Radio Frequency Identification) [16] enabling a simple and safe two-way interaction between electronic devices, and allowing users to perform contactless transactions, access digital content and connect devices with a single "touch". In other words NFC is a mobile device with RFID technology with the capacity to function in active and passive mode. Thus, the NFC device has the ability to read/write information onto the RFID-chip and to establish peer-to peer communication between two NFC devices.

Thus, NFC offers a simple solution based on the "touching paradigm" where users, with their NFC device, touch everyday life objects augmented with visual marks and RFID Tags, with the aim of triggering intelligent services offered by those objects $[39,44]$. Nowadays, different investigations are studying the use of NFC for a wide spectrum of problems, including commerce, ticketing and payment, transport, tourism, identification and security, university, among others [19,34-36,42].

Therefore NFC is a useful technology in the development of the Internet of Things [17] generating not only commercial applications for identification, payment or ticketing, but any kind of service in any kind of environment or scenario.

The educative environment is one of them, giving rise in recent years to the idea of the University of Things (UoT) based on the application of the Internet of Things (IoT) concept to the university environment [37]. The central idea of this paradigm is to bring the university close to students and workers, as well as the whole of society in general; offering university services which may be available anytime and anywhere.

With this aim, Aittola et al., [3] describe a location-aware mobile library service which provides map-based guidance to books and collections on PDA. Solution, called "SmartLibrary", helps users to find books and other material from the library. This system shows the user a map to locate a source in the library. Solution can access the online resources anywhere within the library using a mobile device.

The proposal described in this paper increases the goals of this contribution, relating any kind of bibliographic sources with learning activities and contents, helping students with access to bibliographic sources and study of the main and recommend contents corresponding to the subject and knowledge necessary for their university learning.

Our goal is the monitoring of students by teachers, to give support to students in their study by promoting access to personalized bibliographic sources, guiding them to specific sources (articles, books, and any kind of recommended bibliography) that need to be accessed by students in order to acquire the required knowledge in each of the disciplines. In addition, our proposal facilitates teacher-student communication, offering pervasive methods to teachers so that they can advise students in the learning process and students can communicate with teachers to establish contact and resolve doubts.

Our work is focused on the use of existing ontological standards (Learning Technology Standards Observatory, LTSO [32]) for the proposal of an ontology for describing custom teaching guides. Specifically, we have made use of the IMS Learning Design (IMS-LD) [22] standard which offers a way to describe learning activities and their organization. The ontology contents are related to bibliographic information "chunks" which have been recommended 
by teachers in order to improve the understanding of the subjects and the development of expected skills.

Moreover, this study is focused on the use of NFC technology to build a customized system devoted to help university students to access, read and review the necessary bibliography sources for the development of their learning.

Basically, our system has an architecture based on a back-end system responsible for the management of the information about teachers, students, teaching guides, etc., and a front-end system based on an NFC enabled device. The front-end system is designed to be used for students anytime and anywhere in a personalized way. Its main application area is university libraries, giving students access to the main and recommended specific contents of the bibliographic sources located in the library. In addition, the frontend system allows students to search for personalized and generalized information about bibliographic sources, subjects, content and teachers' notes and recommendations, etc., anytime and anywhere.

With this aim, we propose a pervasive solution based on Web-services and the use of NFC technology. When a student "touches" a bibliographic source, he/she receives personalized information on his/her NFC device about the information elements that this source can contribute to his/her academic and professional training.

In order to apply and test this approach, a tool called Pinakes (Pervasive and INtelligent system for the Awareness Elicitation for Students) has been created. Pinakes gives access to information about bibliographic sources which has been augmented through an NFC Tag.

Pinakes works with different scenarios: a) the library building where the bibliographic sources are located; in this environment users go and, by touching a source, retrieve appropriate information, b) the teacher's office doorway or classroom or any other place where post-its related to teachers are located; students can retrieve information related to the teacher as well as ask the teacher for a meeting, for instance, and c) anywhere students can execute services related to access to subject and content information or news provided by the teachers.

Figure 1 shows the Pinakes scenario where the bibliographic sources offer the user different services within the university environment. Thus, when a student touches the Tag associated to a book, for instance, he/she can retrieve general as well as personalized information. The mobile application sends a side request to the server with information about the user and the bibliographic source. Information stored

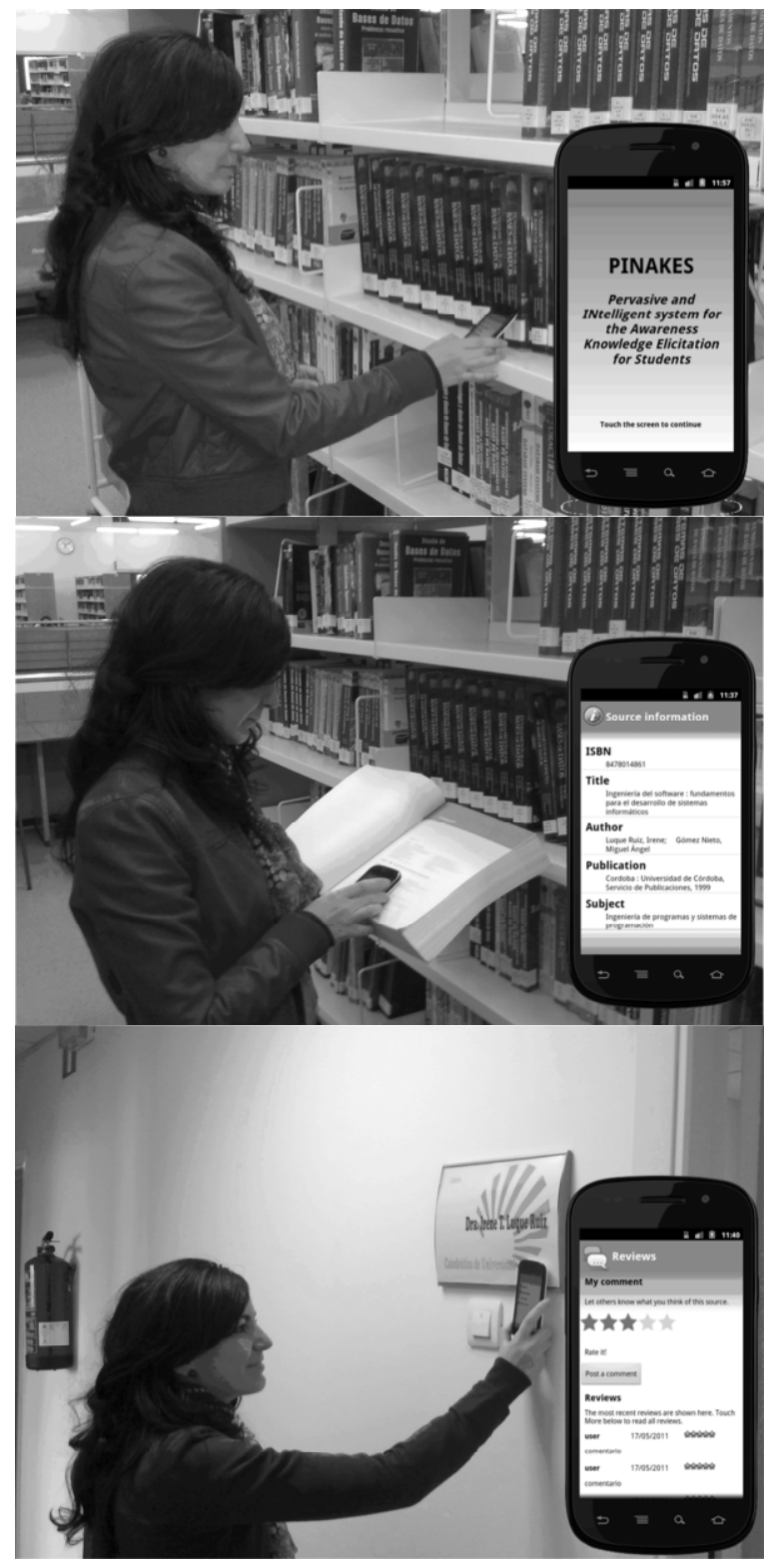

Fig. 1. A example of the Pinakes scenarios.

in the server about the book, main contents, advised contents and tailored information for the student is sent back and shown on the mobile screen. Later, the mobile application guides the user to access to the source, to read a specific issue or request new information or services.

Furthermore, as is shown in Fig. 1 (bottom), Tags associated to teacher's office doorways (or any other location) can be used for students to retrieve general or specific information, as well as enabling students to send communications to the teachers. 
In Related work section we comment the existing solutions related with our proposal. These studies propose ontological models for representing the information of the learning process and technological solutions for the development of appropriate implementation scenarios. We describe in this section how Pinakes take the advantage of the existing ontological models, extending them for the building of a pervasive solution using mobile phones and NFC technology.

The paper has been organized as follows: in Section 2, the learning design specifications and the Pinakes ontology proposed are described. In Section 3, the proposed solution is presented, describing the system architecture and the interaction model between the different system components, showing in Section 4 the Pinakes mobile application and in Section 5 describing the validation of the system. Finally, related works is discussed in Section 6 and in the Discussion section we comment the results and our future works.

\section{Pinakes ontology}

The specifications for the learning design, known as Educational Modelling Languages (EML), are models of semantic information and aggregation describing, from a pedagogic point of view, the content as well as the educational activities [4]. These elements are organized into study units with the aims of allowing their re-use and interoperability [41].

Moreover, EMLs facilitate the description of pedagogic aspects that are related to learning objects (LO) in educational process. The main standard specifications are:

- IMS Learning Design (IMS LD) [22], drawn up by the IMS/LDWG work group, is an integration of the EML developed by the OUNL, with other existing IMS specifications for the exchange and interoperability of e-learning material. IMS LD describes the structure and educational processes based on pedagogic metamodel, using units of learning called Learning Design. A unit-of-learning may represent a course, a module or a lesson containing one or more educational objectives. IMS LD describes a method that is made up of a number of activities carried out by both learner and staff in order to achieve particular learning objectives.

- EML-OUNL [14] is a meta-vocabulary based on the diversity of concepts existing in a wide range of pedagogic techniques. EML-OUNL offers a meta-model based on the description of activities having to be carried out by student roles and teachers in certain environments. The central element is the concept of unit of study which is considered as the smallest unit satisfying one or more educational objectives. This means that a unit of study cannot be decomposed into parts without loss of its effectiveness in achieving educational goals.

- PALO [40] is a modelling language that has been developed by the UNED (National Distance Education University, Spain). PALO uses the concept of module as a unit of study describing courses organized into modules containing learning activities (description of exercises) and contents (concepts, problems, and others). These contents and activities are structured hierarchically to establish the execution sequences.

The metadata specifications are useful to describe educational resources, and therefore to facilitate interoperability and re-use between learning software platforms, due to the fact that they represent the vocabulary describing the different aspects of the learning design process. However, the main drawback is that the meaning of the specification is usually expressed in natural language. In order to solve this problem, ontologies come in handy to describe formally and explicitly the structure and meaning of the metadata elements; that is, ontology would semantically describe the metadata concepts.

\subsection{The proposed model}

The aim of the Pinakes ontology is to capture the knowledge needed by the teacher to carry out the planning of the learning objectives and to specify the learning activities, prerequisites, methods and resources/contents that will be used on a course. Through this ontology, we can define customized teaching guides. The contents of these teaching guides are related to bibliographic information, which is recommended by the teacher to achieve the learning objectives.

This ontology is based on the IMS Global Learning Consortium specifications [23], which are rooted in the Educational Modelling Language (EML) and it incorporates all concepts contained in the conceptual model of the IMS specification level A.

The IMS LD specification is a meta-language that describes all elements of the design of a teaching- 


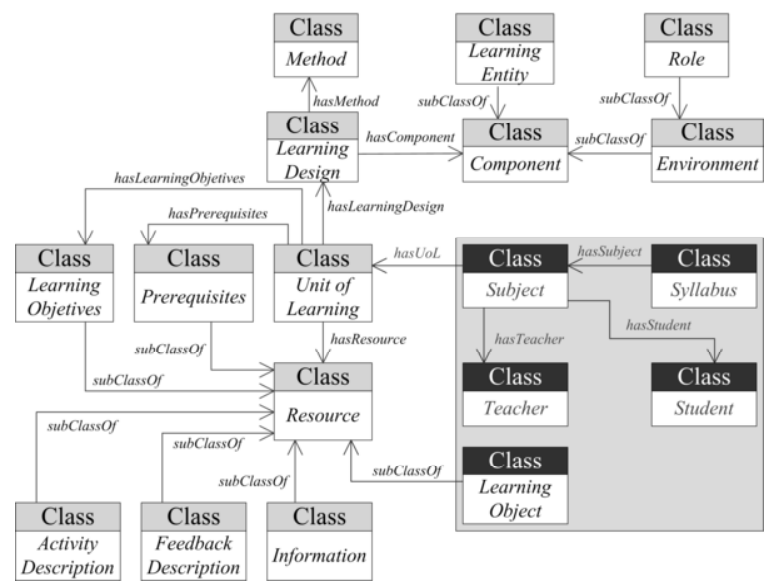

Fig. 2. Upper concepts of the Pinakes ontology.

learning process. This specification has been formally modelled through the XML-Schema language [4].

In our proposal, we make use of the IMS standard for defining Units of Leaning, an integral part of a learning process. A Unit of Learning is an integral part of any Subject and a set of subjects represent a Syllabus.

The upper node of the Pinakes ontology is the Syllabus concept that defines the set of subjects, practices, studies and other learning activities that determine the content of an educational program.

The classes represented with dark boxes in Fig. 2 show the new terms added to the specification. Consideration of Student and Teacher classes allows us to represent the relationship between these actors and the subjects. Thus, the services provided by the system can be customized for each student and teacher.

We have modelled the IMS LD elements in a concept taxonomy in which relations between the concepts are explicitly represented. We have identified the most important concepts, classifying them according to the criteria for constructing taxonomy to guide the process of building the corresponding ontology. Thus, the ontology elements are organized as follows:

- Unit of Learning concept defines a general module of an educational process, such as a course or a lesson (Fig. 2). We have considered a unit of learning as a lesson that belongs to one subject. A unit of learning integrates the description of both the learning design and the set of resources related to it.

- Resource concept allows representing various entities, such as physical resources (Web pages,

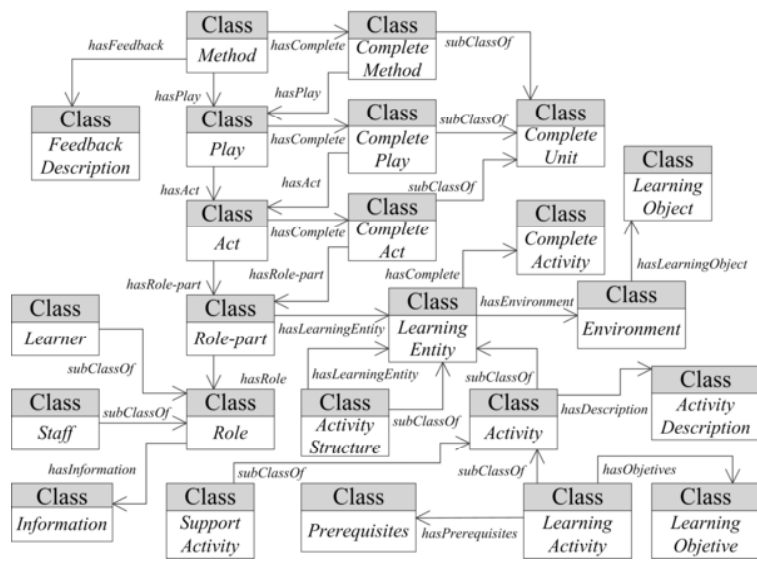

Fig. 3. Concept taxonomy that describes the dynamics of learning design.

files, etc.), and concepts whose attribute description is domain-dependent (Learning objectives, Prerequisites, etc.).

- Learning Design concept is a description of a method enabling learners to attain certain learning objectives by performing, in order, some learning activities in the context of a learning environment. Learning Design starts with the Learning Objectives and Prerequisites definition.

- The Learning Objectives and Prerequisites define the intended outcomes when the unit of learning is carried out, and the previous knowledge needed to participate in it, respectively. The IMS specification for learning objectives and prerequisites can be basically considered as textual information or as resource.

- Components concept provides the "building blocks" of the learning design: learning entities, roles and environments. These elements are: a) Roles participating in the execution of activities, b) Learning Entities which can be activities or group of activities, and c) Environments describing the educational resources to be used in the activities (see Fig. 3). These concepts constitute an exhaustive and disjoint partition, because an instance of a Component must necessarily be an instance of one of its subclasses.

- The Learning Entities are the activities to be carried out, which can be Activities or Activity Structures. An Activity is a set of learning acts performed to achieve an objective and the sequence of all the activities will determine the "learning workflow" in a learning design. The IMS LD specification considers two different 
activities: Learning Activity as a set of acts performed by students using learning resources within an environment to achieve certain objectives, and Support Activity referring to activities that are not carried out to achieve a certain objective but supporting the learning activities. When activities are grouped an Activity Structure is defined which can also group other activity structures.

- The Role concept specifies the participants of the learning process. According to the IMS specification there are two basic roles: Learner and Staff.

- Activities are carried out in an Environment containing resources used by the roles in the development of a learning activity. According to the standard, a Learning Object is a resource that is used to carry out a learning activity. For our proposal, we have considered a Learning Object as a bibliographic resource. This learning object is used to represent the Tags information associated with a bibliographic source. This information represents the bibliographic sources that a student should consult to complete his/her learning. The Learning Object concept has been modified to fit in with Pinakes requirements.

- Learning Design concept is also related to the Method concept, which describes the dynamics of the learning process (Fig. 3): a method is composed of a number of instances of the Play concept that may be interpreted as the runscript for the execution of the unit of learning. All the play instances have to be executed in parallel, and each one consists of Act instances, which may be understood as a stage of a course or module. The Act instances must be executed in sequence and they are composed of a number of Role-Part instances that will be executed concurrently. A Role-Part associates a Role(s) with a Learning Entity to be carried out in the context of the act.

- Every concept involved in the dynamics of the learning process (Method, Play, Act and Activity) establishes a relation with one of the subclasses of the Complete Unit concept indicating when an execution is finished. In the IMS LD Level A, this condition can be specified through the time limit attribute, which defines the temporal duration of the execution, or refers to an instance of the entity of which it is composed.

- The IMS LD specification defines other important elements providing detailed information

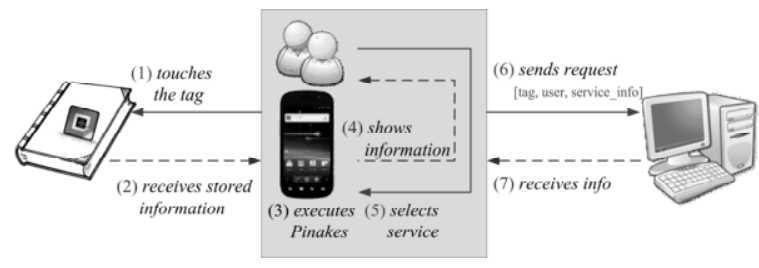

Fig. 4. Interaction flow for bibliographic sources.

about an element of the learning design: Information, Activity Description and Feedback Description.

\section{Pinakes: Pervasive system NFC-based}

The development model for intelligent ambients using NFC technology and applied to university environments described in this paper is based on the use of the "Touch Computing" paradigm as a swift, easy, and intuitive model for bringing the university close to students and workers, as well as society in general, offering university services to be available anytime and anywhere.

Figure 4 shows the general architecture of the proposed solution which is based on the use of three actors: a) smart objects augmented with RFID Tags disseminated in the university environment, b) users, using NFC mobile phones storing appropriate software, and c) a back-end software in charge of dispatching the user requests.

As Fig. 4 shows, when the user "touches" any of the Tags associated to a bibliographic source with his/her NFC device (flow 1), if Pinakes mobile application is not running in the mobile phone, it is started (flow 3) and the information stored in the Tag is received (flow 2). The Tag associated to bibliographic sources stored the main information about the issue, that is, library reference, ISBN/ISSN, title, authors, etc. This information together with the unique identification of the RFID Tag is received in this step.

Pinakes mobile application shows this information to the user (flow 4); next the user decides to request some of the defined services (flow 5). Then, a GPRS/EDGE/UMTS communication is established with server side, sending information about the user identification, requested service, and Tag and bibliographic source identification (flow 6).

Finally, the request is executed on the server side, sending back the information requested to the mobile application (flow 7), and the mobile application being responsible for showing the answer to the user in a proper way. 


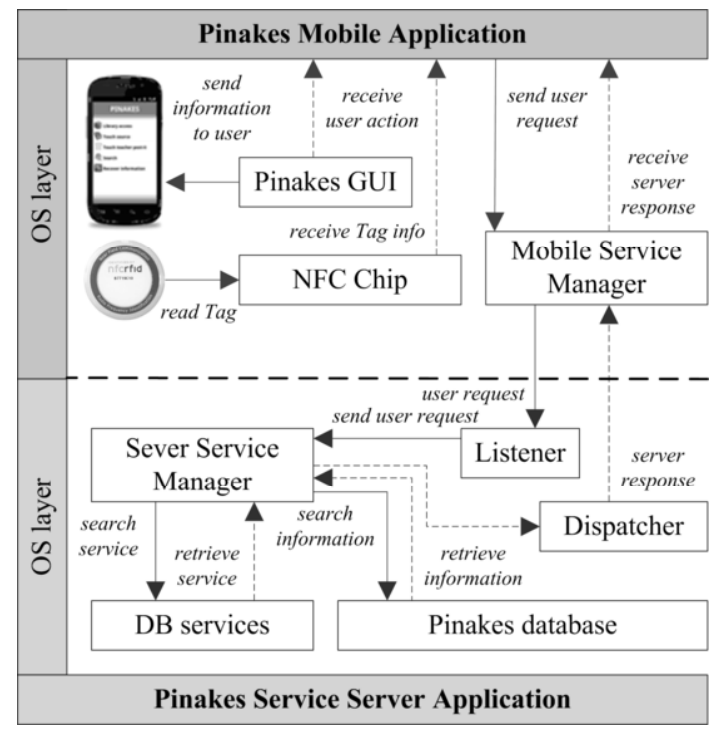

Fig. 5. Interaction flow between Pinakes components.

\subsection{System architecture and interaction between Pinakes components}

Pinakes involves two main components or subsystems: Pinakes mobile and Pinakes server. The mobile application allows the user to interact with real objects by means of the NFC, as well as to communicate with Pinakes server in order to request general and personalized information. Pinakes server involves two different subsystems in charge of: a) the management of the information (Web portal), and b) the dispatching of the user requests. Pinakes Web portal manages the information using the ontology described above in this paper, allowing the teachers to manage the "chunks" of information and to link theses chunks to subjects, students and bibliographic sources. Moreover, Pinakes server includes a set of functionalities in charge of the communication with Pinakes mobile application and to respond to the user requests by retrieving the information from the database.

Figure 5 shows the main architecture of these Pinakes subsystems. Pinakes interacts with a smart scenario augmented with RFID Tags. The Tags are Mifare 4K [38] labels associated with an object (a bibliographic source in this case). The Tags store information related to the source. This information is gathered by the mobile application allowing the user to request any of the defined services to be dispatched by the server.

The mobile application is a Java application developed in Android OS [6] and the users must have it installed on their mobile devices in order to obtain the services offered. This application is executed in the NFC device guiding the user interaction as follows: a) read Tag information, b) shows information, c) offers a set of options to users, and d) establishes communication with the server to get user requests.

The server application is a Java application developed in J2EE platform [27]. This application is necessary for teachers to define the syllabus. The server is responsible for: (a) registering the contents of the syllabus customized; this content is recorded by the teacher who is responsible for providing the necessary bibliographic sources to complete student learning, and (b) providing the information and services requested by the user by means of the Pinakes mobile application.

As we can observe in Fig. 5, when the user "touches" a Tag associated with a bibliographic source with his/her NFC device, thanks to the information stored in the Tag, the application stored in the mobile device is automatically instantiated. This event is carried out thanks to the "intent filter" method [27]. The core components of an application are activated by intents. An intent is a bundle of information describing a desired action, including the data to be acted upon, the category of component that should perform the action, and other relevant instructions.

When the mobile application has not been previously installed in the NFC device, a message alerting for the need to download it from the server is received. Once the mobile application is downloaded and installed in the device, the user can configure it.

Figure 5 shows the process flow and communication between the Pinakes components. Information read from Tags by users using the NFC component of the mobile phone is managed by Pinakes mobile application showing it in an appropriate way using the GUI component. The user can visualize the information received from the Tag and to choose the desired action/service from among what is available. Preferences defined by the user using the "Configuration option" of the mobile application determine how the information is shown, as well as how the communication will be performed with Pinakes server side. The user request is sent to the server side using the Service manager component. This component is an agent responsible for communicating with the server side, sending the user request and receiving the information from the server.

Pinakes Server has a listener service in charge of receiving user requests. Requests are managed by the Service Manager component of the server that has 
access to the database of registered services, selecting the appropriate service to answer the user request. Then, the service is executed retrieving the necessary information from Pinakes database and using the Dispatcher service to send back the requested information to the mobile application.

Services have been implemented using Java language and defined using Web Service Description Language (WSDL) [23]. These services are Java applications which respond to client requests (computers or mobile phones).

Thus, as Fig. 5 shows, we propose a service model which aims to enable rapid prototyping of contextaware services in pervasive computing environments [21]. Context-aware mobile services [12,15] are applications and services that make use of different level of contexts and adapt the way they behave according to current contexts. To construct contextaware mobile services, a common way is to specify actions that are triggered by a set of rules whenever the current context changes. These rules use user preferences.

Our context is formed by a set of objects which are augmented through RFID/NFC Tags. Depending on the Tag type (if is a Tag associated to a bibliographic source or a post-it) and depending on the available information related to the object associated with the Tag (book, journal, digitalized source, subjects, etc.) and the actors (student and teacher) related to the interaction, different services can be offered and therefore dispatched. In addition, the user preferences, the technology currently available and the environment will determine how the services are dispatched and how and when the user has access to them.

\subsection{System components interaction}

Figure 6 shows the UML interaction diagram corresponding to the interaction process among the system's components. When the user touches a Tag the mobile application reads the information stored in the Tag and the Tag identification (unique for each Tag). Next, the information is shown to the user, allowing the user to select the desired action.

Once the service is selected, the request is sent through the communication module of the mobile phone to the server side, where a listener service would receive the request and process it.

The listener is an agent in charge of receiving any request from the mobile application. The mobile application requests are: (a) information or services about a source, (b) information about advice, reviews

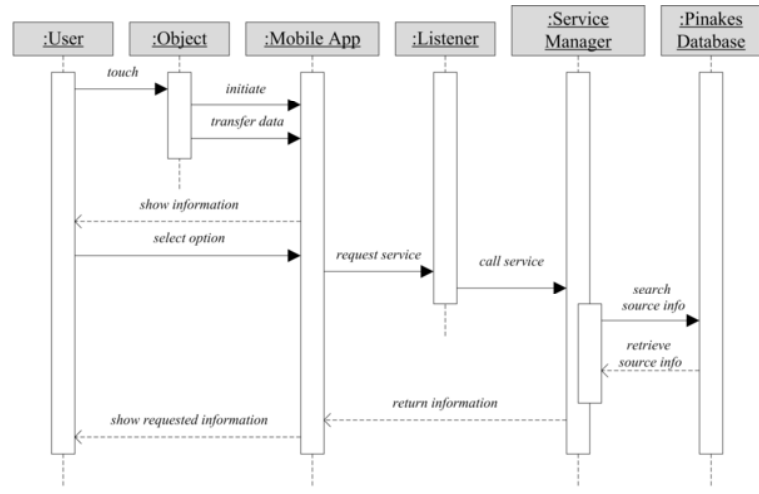

Fig. 6. Sequence diagram of the user interaction with bibliographic sources.

and uses of a certain source, (c) teacher notes, (d) library access, (e) search source information, (f) and others described below.

When the listener receives a request, analyzes it and transmits it to the Service Manager. Service Manager checks the request in the database of registered services, selecting the appropriate service to respond to the request. Next the service is executed retrieving the information from the Pinakes database and sending back a response to the mobile application by means of the Dispatcher service (see also Fig. 5). Then, the mobile application is in charge of formatting the answer properly for the user, offering the programmed functionality for the handling of the information received.

\subsection{Augmented objects and NFC readers interacting with Pinakes}

As mentioned previously, the scenario is an open and intelligent environment thanks to the smart objects which are augmented with RFID Tags. Pinakes application works with different types of smart objects.

The main smart objects are the bibliographic sources. A bibliographic source represents any book, journal, magazine, manual, etc., available in a university library. These sources are tagged with Tags. These Tags store information about the source, so the user can request a set of services related to the source.

Moreover, Pinakes works with post-its. A teacher post-it is a smart object located in the teacher's office (or any other place, such as the classroom door). These objects store information about the teacher (schedules, suggested bibliography, etc.). 


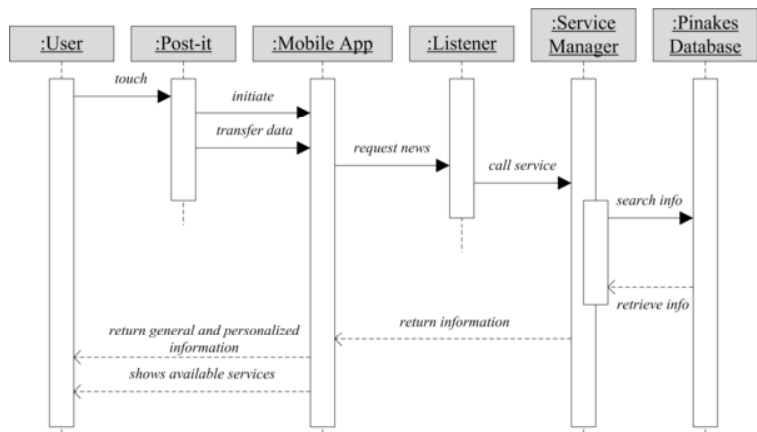

Fig. 7. Sequence diagram of the system for a post-it service.

Students touching teacher post-it objects can retrieve updated information related to a subject that the teacher has stored for them. These objects can include other types of services the students may request.

An example is shown in Fig. 7. When a student touches the post-it corresponding to a teacher, information stored in the Tag is transferred to the mobile application. Next, the mobile application sends the server side a request for news, if any exists. In this request the mobile application sends the identification of student and the Tag.

The Service Manager on the server side receives this request and executes the corresponding service in charge of searching information in the database. Finally, the retrieved information is sent back to the mobile application, showing the user general and personalized information stored by the teacher, as well as the available services to be selected.

Tags associated to teacher post-its only store information related to teachers and/or subjects. This information is transferred to the server side together with student identification and it is the server who determines the response corresponding to the input data, that is, learning teacher information, teacher information for a subject and/or for a student.

In addition, we have considered the development of a fully based library scenario. Thus, Pinakes also works with NFC readers. An NFC reader is an object located in a university library. NFC readers can be used by librarians to control student access, loaning of books, etc., substituting the use of barcode readers.

\section{Pinakes mobile application}

Pinakes mobile application is a Java application for NFC mobile phones. The tool allows getting information about a source with an NFC Tag attached

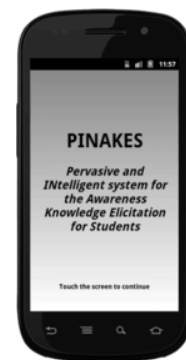

(a)

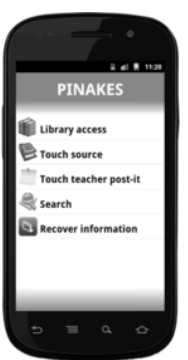

(b)

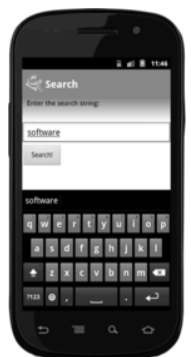

(c)

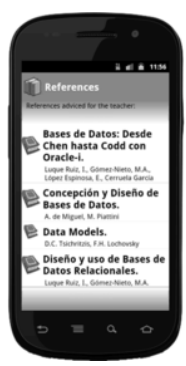

(d)
Fig. 8. Some Pinakes snapshots.

storing the information about the source and the service or set of services offered to the user.

We have developed a prototype which uses the information that has been defined through IMS-LD ontology previously described. The prototype user interface is developed on top of the Android platform and tested on Nexus-S smart phone [43].

Figure 8 shows some snapshots of the application's interface. When the mobile application is instantiated by the user (Fig. 8a), a list of options are shown to the user (Fig. 8b), allowing interaction with all the "smart objects" considered in the systems: Tags associated with bibliographic sources, Tags associated with teacher post-it, NFC readers located in the library for access control, for instance, and general search and recover options.

The information received by the user in previous interactions may be stored for future accesses and requests. All information is stored in the mobile device, the location being chosen by the user in the "Configuration" options. The user can, at any time, manually or guided by the application, delete the historical information stored in the device.

Furthermore, during the search process (see Fig. 8c), the mobile application allows the user to include some search criteria. Once the search criteria have been chosen, the mobile application sends the request to the server which answers back with a list of bibliographic sources fulfil the current search criteria (see Fig. 8d).

This functionality can be performed at anytime and anywhere and it is not necessarily related to touching activity. Thus, users may perform searching for any content stored in the database: books, recommended books for a subject, recommended information content for issue and so on.

When a Tag in a source is "touched" with the NFC device, the main information about the source is shown on the mobile screen (Fig. 9a). This information is stored in the Tag, so no connection is neces- 


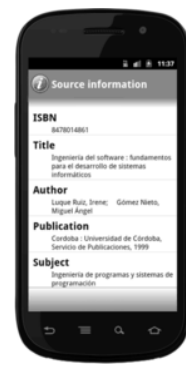

(a)

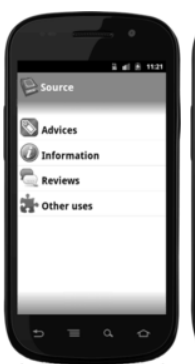

(b)

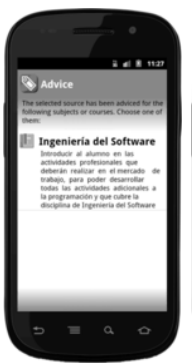

(c)

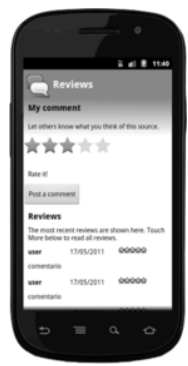

(d)
Fig. 9. Snapshots of the interaction with bibliographic sources.

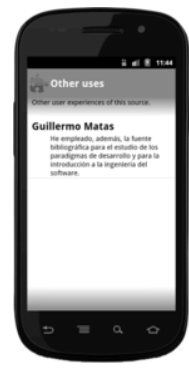

(a)

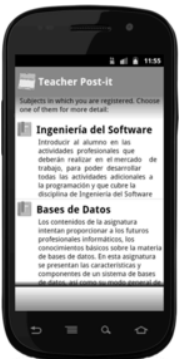

(b)

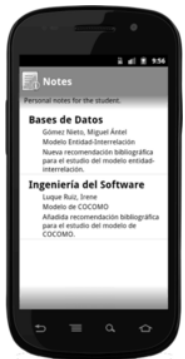

(c)

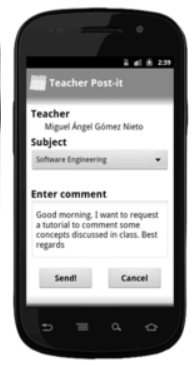

(d)
Fig. 10. Snapshots corresponding to other Pinakes functionalities.

sary with the server for this action. Then, users can select between a set of options considered in the system for this kind of Tag (Fig. 9b). Thus, personalized or general advices about the source can be accessed (Fig. 9c). The advice show the subjects and learning activities corresponding to the recommended bibliographic source.

Furthermore, students can write some comments about the source, to evaluate the utility of the source and to review other evaluations performed by other users (Fig. 9d).

Moreover, teachers and students can choose bibliographic sources for other subjects different from those assigned on the courses (Fig. 10a). This functionality included in the system allows student to share the information and its utility in the learning process.

Tags located as post-it on teacher's door, office or classroom, for instance, allow students to retrieve information closely related to the teacher and the learning activity. Thus, as Fig. 10b shows as a post-it is touched, the information about the subjects related to the teacher is shown, allowing the students to ask for information about them.

News about the subject written down by the teacher in Pinakes database can also be retrieved (Fig. 10c). This news could inform the students of any matter about the teaching process; e.g., new information added to Pinakes portal, change of the class schedule, tutorial timetable, etc.

In addition, students can write notes to the teacher (Fig. 10d). This option allows the students, for instance, to request a tutorial meeting with the teacher or to ask for some information related to the learning process. When a student writes a note in a post-it, this information is not stored in the Tag associated. In this process a communication is established with the server side and the information is stored in the server database. In addition, a service is instantiated in real time, sending an email to the teacher.

\section{Validation of the proposal}

In order to put our proposal into practice and validate the user acceptance of the approach, we have carried out a system testing evaluation at the University of Córdoba. Fifteen students participated in the experiment ( 5 female and 10 male). As the participants did not know the NFC technology, they were provided with a brief explanation (10-15 min) of its characteristics, the capabilities of a NFC mobile, and its operation. Then, the NFC device was offered to the participants for system evaluation.

Once the user interaction was finished, and all the doubts raised by the users were resolved (the most usual was whether the mobile phone owned by the user had the capabilities of the NFC device used during the experience), they had to answer a small questionnaire related to the experience.

Our goals for this study were several: a) study of the user acceptance and usability of NFC technology, b) user evaluation of the system, analyzing all subsystems and functionalities, c) capacity of the ontology used to adapt to the current subject curricula, d) usefulness of Pinakes to access to bibliographic sources of the university library, e) student acceptation of the system for access to recommended and usefulness contents related with subject, and f) general acceptation of this kind of application to be applied in the new learning environment.

However, for this study we only had a small number of students and this study can only be applied to the subject responsibility of the teachers involved in the research. Currently, the system is a prototype not implemented at the University of Córdoba due, in part, to political and economic reasons. In spite of that, as we describe below, excellent results were obtained in the study carried out. 
In order to evaluate the user acceptance, we used an adapted IMB Post-Study questionnaire [30] which allowed us to measure user satisfaction with system usability. The survey consisted of the following questions that had to be evaluated between 1 (very low) and 5 (very high):

Q1: Overall, I am satisfied with how easy it is to use the system.

Q2: It was simple to use the system.

Q3: I could effectively complete the tasks and scenarios using the system.

Q4: I was able to complete the tasks and scenarios quickly using this system.

Q5: I felt comfortable using this system.

Q6: It was easy to learn to use the system.

Q7: The information provided with this system was clear.

Q8: The organization of information on the system screens was clear.

Q9: The interface of this system was pleasant.

Q10: Overall, I am satisfied with this system.

Participants were between 19 and 25 years old, twelve of the fifteen were familiar with the use of a Smartphone, and three own an Android device similar to the one used in the experiment.

\subsection{Evaluation of the results}

We present the evaluation of the user acceptance for the functionality provided in the scenario. Questions were answered using a 5-point Likert scale (Completely Disagree, Disagree, Neutral, Agree, and Completely Agree). Table 1 shows a summarized of the obtained results.

Most users $(85 \%)$ were satisfied with the system and how to use it. More than $80 \%$ of the people also strongly agreed that by using the system they were

Table 1

Results of users' experience with the systems expressed in percentage. E: completely disagree, D: Disagree, C: Neutral, B: Agree, A: Completely agree

\begin{tabular}{lcrrrr}
\hline Question & $\mathrm{E}$ & \multicolumn{1}{c}{$\mathrm{D}$} & \multicolumn{1}{c}{$\mathrm{C}$} & \multicolumn{1}{c}{$\mathrm{B}$} & \multicolumn{1}{c}{$\mathrm{A}$} \\
\hline Q1 & 0.00 & 0.00 & 20.00 & 13.33 & 66.67 \\
Q2 & 0.00 & 0.00 & 0.00 & 13.33 & 86.67 \\
Q3 & 0.00 & 0.00 & 0.00 & 6.67 & 93.33 \\
Q4 & 0.00 & 0.00 & 20.00 & 20.00 & 60.00 \\
Q5 & 0.00 & 0.00 & 0.00 & 0.00 & 100.00 \\
Q6 & 0.00 & 0.00 & 0.00 & 53.33 & 46.67 \\
Q7 & 0.00 & 13.33 & 13.33 & 40.00 & 33.33 \\
Q8 & 0.00 & 0.00 & 40.00 & 40.00 & 20.00 \\
Q9 & 0.00 & 20.00 & 20.00 & 13.33 & 46.67 \\
Q10 & 0.00 & 0.00 & 6.67 & 53.33 & 40.00 \\
\hline
\end{tabular}

able to complete the tasks and scenarios effectively and quickly.

More than $85 \%$ of users agreed or strongly agreed that the interfaces were pleasant and clearly organized and all the subjects considered that the system is simple to use and they felt comfortable using this system.

Finally, more than $90 \%$ of users agreed or strongly agreed that they were satisfied with this system.

Although the initial results of the experiment show that by following our approach we can greatly facilitate users with access to bibliographical sources, additional experimentation would be required to analyse the user acceptance of the system over longer periods.

\section{Related works}

Pinakes is a pervasive system aims providing students the access to bibliographic sources recommended by teachers on the subjects or courses on which the student are enrolled. Teacher recommendations are defined as knowledge chunks that students should access in order to get the necessary knowledge about a subject or course. Thus, the knowledge chunks could be any content included in a bibliographic source (a definition, a book chapter, a research paper, etc.).

The main characteristic of Pinakes is that students can access to bibliographic sources anywhere and anytime using their mobile phone and NFC technology, consulting both overall and personalized teacher recommendations. Furthermore, students can provide to other students recommendations about the quality or utility of the teacher ones.

Pinakes is based on IMS-LD standard to define the ontological model leveraging the proposals of other authors and extending them to define the Pinakes ontological model as we comment in this section.

In addition, in this section, we comment proposal where mobile phone and QR or RFID technologies have been studied for library applications, demonstrating that NFC technology provides a new and more intuitive interaction model.

Amorim et al. [5], define EUME as an educational ontology describing terms of learning design, contents and resources with the aims to support traditional learning as well as other emerging methodologies, such as collaborative learning. Our proposal extends this model including new class allowing represent the new characteristics considered by Pinakes solution. 
Knight et al. [28], describe an ontology-based framework for bridging learning design and learning object content. They develop a conceptual model and create an ontology called Learning Object Context Ontology (LOCO) based on the IMS LD. Pinakes uses the learning objects considered in LOCO to represent the bibliographic sources as part of the learning design.

Gómez et al. [18], study some specifications, architectures and technologies that can be used in content adaptation processes by considering the characteristics of the context to design units of learning based on IMS LD specification. Our proposal is also based on IMS LD extending it by the consideration of new knowledge chunks and entities allowing the consideration of general and personalized contents for students.

Chu et al. [10], propose an approach for developing and employing libraries to support context-aware ubiquitous learning, describing the butterfly and ecology electronic library. Moreover, an innovative approach based on the repertory grid method is proposed to assist teachers to develop context-aware ulearning activities with learning content retrieved from electronic libraries. A practical application has been conducted on an elementary school to evaluate the performance of the innovative approach. This work is not based on providing information on bibliographic sources recommended in a university library. They provide a mechanism for building an electronic library on a specific topic to help students in their learning. We present a proposal to make use of existing resources in university libraries.

Wilson et al. [50], illustrate how library services can be adapted to the mobile environment and how the library can play a role in broader campus mobile initiatives, and Walsh [46] presents the use of QR codes at the library of the University of Huddersfield, outlining and also looking forward the potential use of alternative technologies such as RFID to deliver similar types of information. The development is focused to services such as: links to electronic resources, instructional videos, and useful websites for further information and as a way of storing information for future reference. Our contribution advance in these proposals using NFC technology (a technology more secure, easy to use and quick than QR) and incorporating in Pinakes functionalities devoted to pervasive services of the library.

Wang et al. [47], describe an adaptive u-learning system was developed in the lifelong learning context in combination with associated learning theories as well as context-aware technology. The design of the study's courseware recommendation model uses the lifelong learner characteristics, learner behavior and learning preferences to make appropriate courseware recommendations. This study shows the benefits of using mobile learning models. Also, authors show a study to add RFID technology to the learning and the benefits of using this technology. With these results, we base our work on the use of NFC technology in the learning process.

A location-aware book recommendation service that most closely resembles the work here is the example from Chen and Yang. Chen and Yang [9] describe a system for location-aware book recommendations, using a system architecture close related with the proposed in this paper, modeling the problem based learning using services in charge to recommends resources based on user data and learning objectives. It should be noted that this model was implemented in a vocational high school library in Taipei, Taiwan. In our approach, we do not define recommendations to students based on their location. We provide information to the student when he/she interacts with a bibliographic source.

\section{Discussion and remarks}

In this paper, we have presented a pervasive and context-aware system for access to bibliographic sources. The solution based on an ontology describing the learning process permits the relationship of bibliographic sources, or part of them, with knowledge chunks involved in the activity of the learning process. The aim is to support compliance with the EHEA directives.

Users need just a single NFC-enabled phone for interacting with the set of smart objects spread throughout the university environment considered. The main smart objects are bibliographic sources which are augmented by RFID/NFC Tags or post-it related with teachers located at teacher's office doorway, for instance.

The system composed of a Web portal devoted to the management of the knowledge chunks related to the subject contents and learning activities allow teachers to relate this information to the recommended sources to be studied by students, allowing teachers to establish general and personalized activities and recommendations. Students using and mobile NFC-enabled phones can perform searching actions at anytime and anywhere, receive news from teachers, touch a bibliographic source and retrieve teacher suggestions as well as ratings and recommendations 
from other students, in an easy and intuitive interaction.

The set of functionalities defined by the described system are performed by a set of specialized services managed by the server subsystem. These services collect the user request and initialize the necessary service access to the database, sending back to the user the requested information.

The learning model based on the Bologna declaration encourages students to learn to acquire the skills necessary to achieve the required knowledge, which is free to access for the study of necessary bibliographical sources. For this goal, we described in this paper a useful tool to give students access to the main and necessary information from the sources related to the necessary concepts belonging to the subjects. Moreover, the system allows, in a pervasive way, a close relationship between teacher and student, exchanging information related to the learning process.

Currently, Pinakes is an operating prototype that is being proposed for the study of its near deployment. Refinement of the system based on the application test will be carried out for its improvement. We are currently working on the development of new services and new interaction models of interaction. The aim is the building of so-called smart environments and their inclusion at University, having NFC as the main interaction mode. In this way we are trying to create the University of Things [4].

\section{Acknowledgments}

This work was supported by the Ministry of Science and Innovation of Spain (MICINN): Project: TIN2011-24312.

\section{References}

[1] E. Aarts and S. Marzano (eds), The New Everyday: Visions of Ambient Intelligence, Uitgeverij 010 Publishers, Rotterdam, The Neatherlands, 2003, ISBN 978-9-06450-502-7.

[2] H. Ailisto, L. Pohjanheimo, P. Välkkynen, E. Strömmer, T. Tuomisto and I. Korhonen, Bridging the physical and virtual worlds by local connectivity-based physical selection, Personal and Ubiquitous Computing 10 (2006), 333-344, ISSN 1617-4909, Springer, London.

[3] M. Aittola, T. Ryhänen and T. Ojala, SmartLibrarylocation-aware mobile library service, in: Proc. Fifth International Symposium on Human Computer Interaction with Mobile Devices and Services, Udine, Italy, LNCS, Vol. 2795, Springer, 2003, pp. 411-416.

[4] R. Amorim, M. Lama, E. Sánchez and X. Vila, An educational ontology based on metadata standards, in: Proc. the 2nd European Conference on eLearning (ECEL 2003), Glasgow, UK, Caledonian Business School, 2003, pp. 2936.

[5] R. Amorim, M. Lama, E. Sánchez, A. Riera and X. Vila, A learning design ontology base on the IMS specification, Educational Technology \& Society 9(1) (2006), 38-57, ISSN 1176-3647, International Forum of Educational Technology \& Society (IFETS).

[6] Android SDK, http://developer.android.com/sdk /index.html, Accessed: May, 2012.

[7] Bologna Process Official Website, http://www.ond. vlaanderen.be/hogeronderwijs/bologna/, Accessed: January, 2012.

[8] P. Castro Garrido, G. Matas Miraz, I. Luque Ruiz and M.A. Gómez-Nieto, Use of NFC-based pervasive games for encouraging learning and student, in: Proc. Third International Workshop on Near Field Communication (NFC 2011), Hagenberg, Austria, IEEE Xplore, 2011, pp. 32-37, ISBN: 978-1-61284-176-2.

[9] C. Chen and Y. Yang, An intelligent mobile location-aware book recommendation system with map-based guidance that enhances problem based learning in libraries, in: Advances in Neural Network Research and Applications, Lecture Notes in Electrical Engineering, Vol. 67, Springer, Berlin, 2010, pp. 853-860.

[10] H.-C. Chu, G.-J. Hwang and J.C.R. Tseng, An innovative approach for developing and employing electronic libraries to support context-aware ubiquitous learning, The Electronic Library 28 (2010), 873-890, ISSN: 0264-0473, Emerald Group Publishing Limited, West Yorkshire, UK.

[11] T.H. Clausen, Undergraduate engineering education challenged by bologna declaration, IEEE Transactions on Education 48 (2005), 213-215, ISSN 0018-9359, IEEE Education Society.

[12] A.K. Dey and G.D. Abowd, Towards a better understanding of context and context-awareness, in: Proc First International Symposium on Handheld and Ubiquitous Computing (HUC'99), Karlsruhe, Germany, LNCS, Vol. 1707, Springer-Verlag, 1999, pp. 304-307, ISBN:3-540-66550-1.

[13] ECMA, Near Field Communication white paper, ECMA/TC32-TG16/2004/1, Retrieved: January, 2012.

[14] EML Open University of the Netherlands Language, EMLOUNL, http://www.cen-ltso.net/main.aspx?put=223, Retrieved: January, 2012.

[15] M.A. Feki, S. Renouard, B. Abdulrazak, G. Chollet, M. Mokhtari, Coupling Context Awareness and Multimodality in Smart Homes Concept, in: Proc. 9th International Conference ICCHP 2004, Paris, France, LNCS, Vol. 3118, Springer-Verlag, 2004, pp. 906-913, ISBN 3-540-22334-7.

[16] K. Finkenzeller, RFID Handbook: Fundamentals and Applications in Contactless Smart Cards and Identification, 2nd edn, John Wiley \& Sons, England, 2003, ISBN 978-0470-84402-1

[17] C. Floerkemeier, M. Langheinrich, E. Fleisch, F. Mattern and S.E. Sarma (eds), Internet of things, in: Proc. First International Conference (IOT 2008), Zurich, Switzerland LNCS, Vol. 4952, Springer-Verlag, 2008, ISBN 978-3-54078730-3.

[18] S. Gómez, D. Huerva, C. Mejía, S. Baldiris and R. Fabregat, Designing context-aware adaptative units of learning base on IMS-LD standard, in: Proc 20th EAEEIE Annual Conference, Valencia, Spain, IEEE, 2009, pp. 1-6, ISBN 978-14244-5386-3

[19] R. Hardy and E. Rukzio, Touch \& interact: Touch-based interaction with a tourist application, in: Demonstration at 10th International Conference on Human-Computer Inter- 
action with Mobile Devices and Services (Mobile HCI 2008), Amsterdam, The Netherlands, ACM, 2008, pp. 245254, ISBN 978-1-59593-952-4.

[20] R. Hervás, J. Bravo and J. Fontecha, Awareness marks: Adaptive services through user interactions with augmented objects, Personal and Ubiquitous Computing 15 (2011), 409-418, ISSN 1617-4909, Springer, London.

[21] T. Hofer, W. Schwinger, M. Pichler, G. Leonhartsberger, J. Altmann, W. Retschitzegger, Context-awareness on mobile devices - The hydrogen approach, in: Proc. 36th $\mathrm{Ha}$ waii International Conference on System Sciences (HICSS'03), 2003, Hawaii, USA, IEEE, 2009, p. 292, ISBN 0-7695-1874-5.

[22] IMS Learning Design Standard, 2003, http://www. imsglobal.org/learningdesign/, Accessed: May, 2012.

[23] IMS Global Learning Consortium, http://www.imsglobal. org/specifications.htm, Accessed: May, 2012.

[24] ISTAGm, Scenarios for Ambient Intelligence in 2010, European Commission Report (2001), http://www.cordis.lu/ist/ istag.htm, Accessed: May, 2012.

[25] ISTAG, Strategic Orientation \& Priorities for IST in FP6, European Commission Report (2002), Accessed: May, 2012

[26] ISTAG, Ambient Intelligence: From vision to reality, European Commission Report (2003), Accessed: May, 2012

[27] J2EE Platform, http://www.oracle.com/technetwork/java/ javaee/overview/index.html, Accessed: January, 2012.

[28] C. Knight, D. Gasevic and G. Richards, An ontology-based framework for bridging learning design and learning content, Educational Technology \& Society 9 (2006), 23-37, ISSN 1176-3647, International Forum of Educational Technology \& Society (IFETS)

[29] J. Laffey, M. Schmidt, K. Galyen and J. Stichter, Smart 3D collaborative virtual learning environments: A preliminary framework, Journal of Ambient Intelligence and Smart Environments (JAISE) 4 (2012), 49-66, ISSN 1876-1364, IOS Press.

[30] J.R. Lewis, IBM computer usability satisfaction questionnaires: Psychometric evaluation and instructions for use, International Journal Human-Computer Interaction 7 (1995), 57-78, ISSN 1044-7318, Taylor \& Francis.

[31] S. Loke, Context-Aware Pervasive Systems: Architectures for a New Breed of Applications, Auerbach Publications. Taylor \& Francis Group, Boca Raton, FL, USA, 2007, ISBN 978-08493-7255-1.

[32] LTSO, Learning Technology Standards Observatory, http:// www.cen-ltso.net/, Accessed: January, 2012.

[33] I. Luque Ruiz, P. Castro Garrido, G. Matas Miraz F. Borrego-Jaraba and M.A. Gómez-Nieto, University of things: Toward the pervasive university, in: Near Field Communications Handbook, S.A. Ahson and M. Ilyas (eds), Auerbach Publications, Taylor \& Francis Group, Boca Raton, FL, USA, 2011, 153-174, ISBN 978-14200-8814-4.

[34] I. Luque Ruiz and M.A. Gómez-Nieto, University smart poster: Study of NFC technology in university ambient, in: Proc. 3rd Symposium of Ubiquitous Computing and Ambient Intelligence, Salamanca, Spain, Advances in Soft Computing, Vol. 51, Springer, 2008, pp. 112-116, ISBN: 978-3540-85866-9.

[35] G. Matas Miraz, I. Luque Ruiz and M.A. Gómez-Nieto, Applications of near filed communication technology in university environments, in: Proc. IASK International Con- ference of E-Activity and Leading Technology \& InterTIC, Seville, Spain, IASK, 2009, pp. 127-134, ISBN 978-98995806-7-1.

[36] G. Matas Miraz, I. Luque Ruiz and M.A. Gómez-Nieto, How NFC can be used for the compliance of european higher education area guidelines in European universities, in: Proc. 1st International IEEE Workshop on Near Field Communication, Hagenberg, Austria, IEEE Computer Society, 2009, pp. 3-8, ISBN 978-0-7695-3577-7.

[37] G. Matas Miraz, I. Luque Ruiz and M.A. Gómez-Nieto, University of things: Applications of near field communication technology in university environments, Journal of EWorking 3 (2009), 52-64, ISSN 1872-3284, International Consortium for the Advancement of Academic Publication.

[38] Mifare Family by NxP, http://www.nxp.com/\#/pip/pip= $[\mathrm{pfp}=53422]|\mathrm{pp}=[\mathrm{t}=\mathrm{pfp}, \mathrm{i}=53422]|$ Accessed: December, 2011.

[39] NFC Forum, http://www.nfc-forum.org/home, Accessed: December, 2011.

[40] PALO language, http://sensei.lsi.uned.es, Accessed: April, 2012.

[41] A. Rawlings, P. van Rosmalen, R. Koper, M. RodríguezArtacho and P. Lefrere, Survey of Educational Modelling Languages, CEN/ISSS WS/LT Learning Technologies Workshop, Version 1, September, 19, 2002, http://hdl. handle.net/1820/227.

[42] D. Remédios, L. Sousa, M. Barata and L. Osório, NFC technologies in mobile phones and emerging applications, IFIP International Federation for Information Processing, 220 (2006), 425-434.

[43] Samsung Nexus-s, http://www.samsungnexuss.com/, Accessed: May, 2012.

[44] I. Sánchez, J. Riekki, J. Rousu and S. Pirttikangas, Touch \& Share: RFID based ubiquitous files containers, in: Proc. 7th International Conference on Mobile and Ubiquitous Multimedia, Umeå, Sweden, ACM, 2008, pp. 57-63, ISBN: 9781-60558-192-7.

[45] Standards Guidelines for Quality Assurance in the European Higher Education Area, European Association for Quality Assurance in Higher Education, Helsinki, Finland, 2005. http://www.ond.vlaanderen.be/hogeronderwijs/bologna/abo ut/Standards-and-Guidelines-for-QA.pdf, Accessed: January, 2012.

[46] A. Walsh, QR codes using mobile phones to deliver library instruction and help at the point of need, Journal of Information Literacy 4(1) 2010, 55-64, ISSN: 1750-5968, Information Literacy Group, New York: Open Society Institute.

[47] S.L. Wang and C.Y. Wu, Application of context-aware and personalized recommendation to implement an adaptive ubiquitous learning system, Expert Systems with Applications 38 (2011), 10831-10838, ISSN: 0957-4174, Elsevier.

[48] M. Weiser, The computer for the twenty-first century, Scientific American 265(3), (1991), 94-104.

[49] M. Weiser, Ubiquitous computing, IEEE Computer 26(10), (1993), 71-72, doi:10.1109/2.237456.

[50] S. Wilson and G. McCarthy, The mobile university: From the library to the campus, Reference Services Review, 38 (2010), 214-232, ISSN: 0090-7324, Emerald Group Publishing Limited, West Yorkshire, UK. 